\title{
EVALUATION ON IMPACTS OF INFORMATION-DECISION SUPPORT SYSTEMS FOR SUSTAINABILITY OF BUSINESS DEVELOPMENT: A CASE STUDY IN A FIRM
}

\author{
DOI: 10.17261/Pressacademia.2018.877 \\ PAP- V.7-2018(30)-p.181-185
}

\section{Aysenur Erdil}

Anadolu-Marmara University, Istanbul, Turkey. erdil.aysenur@gmail.com, ORCID: 0000-0002-6413-7482

To cite this document

Erdil, A. (2018). Evaluation on impacts of information-decision support systems for sustainability of business development: a case study in a firm. PressAcademia Procedia (PAP), V.7, p.181-185.

Permemant link to this document: http://doi.org/10.17261/Pressacademia.2018.877

Copyright: Published by PressAcademia and limited licenced re-use rights only.

\section{ABSTRACT}

Purpose- This study presents how the structure of information systems can be supported efficaciously in terms of strategic advantage.

Methodology- This research involves a view about the structure of information systems, decision analysis, sustainability of decision support systems and process development according to the defect analysis and also an implementation with a case study in a firm.

Findings- The results according to this topic, A vital component of the response is that business was presented with different perspectivesapproaches in order to integrate innovation and technology to the disposition of the issue-dilemma. Information is used to make decisions. Decision- making structure was applied to identify and understand information system problems of the company. A Model of the information system was suggested to solve the problems and dilemmas in the business.

Conclusion- In this research, The suggested model-structure is closely integrated into the organizational framework, strategic rotation, political modifies, management levels and work system. it supports to obtain new facilities, and also provides to sustain market share and development.

Keywords: Business, decision support system, information, strategy, sustainability.

JEL Codes: Q56, E32, L10

\section{INTRODUCTION}

At present time, technology has a very vital point in every area and it changes rapidly according to the sustainability of management, the product range of large companies and development of operation and organization. Firstly, an information system framework can be explained as a structure of procedures which contains, processes-handles and distributes information to provide control and also supports decision making. In a business, many research areas and subjects involve information about the application of this structure of the system, much more investment approaches, and implementation for this perception.

Contemporary information systems have technical and social effects in an organization. Top management should realize the connectionrelation between the structure, information system-framework and strategies-policy of organizations. This system must be supported the investment of management and decision making operations-processes too (Laudon K.C. and Laudon J. P. 1988; Aier and Fischer, 2011; Blake and Mangiameli, 2013).

Strategic information structures have modified products-services of arrangements and customer relationship, supply chain management, and internal functions. Information technology provides a competitive advantage for many corporations (Kim, and Sanders, 2002; Blake and Mangiameli, 2011).

IT does not provide any information directly but provides some capabilities to the user to analyze the decision problem and generate some meaningful information for decision-making. A properly designed DSS is an interactive software-based system planned to help decision makers and to identify and solve problems and make decisions. Decision Support Systems supply computerized support for the decisionmaking process (Kim, and Sanders, 2002; Blake, R., Mangiameli, 2011; Khademolqorani and Hamadani, 2013).

Generally, an information system can be defined as a set of procedures that collect, process and store information to support decision making and control. There are many different information systems and they support different organizational levels and functions.

Decision Support System is a kind of information system that helps us to make the right decision or making a good investment. Strategic Information Systems have transformed organizations' products and services; relationships with customers, suppliers and internal operations (Druzdzel and Flynn, 2002; Cornou and Kristensen, 2013). 
Most companies store large amounts of data but make very little use of it when it comes to making strategic decisions. There have been significant recent advances in software tools for corporate data analysis. There are wide variety tools available for analyzing corporate data. These tools are sometimes referred to as Decision Support Systems or executive information system. These tools are broken out into a number of different categories for each target at a different set of issues (Meigs, 1993; Laudon K.C. and Laudon J. P. 1988).

\section{LITERATURE REVIEW}

The authors argue that Decision Support Systems (DSS) is a specific class of computerized information system that supports business and organizational decision-making activities. Also, Multiple Criteria Decision Making (MCDM) is concerned with structuring and solving decision and planning problems involving multiple criteria. In this study, an approach is introduced to integrate the DSS and MCDM methods. It causes to the synergy of DSS, through getting more options to analysis, using expert's information, and improving evaluation process (Khademolqorani and Hamadani, 2013).

Defect analysis is a computationally intensive task. Good software tools are essential. There are a number of factors that should be considered when selecting tools for defect analysis. Setting targets and computing rates are at the heart of evaluation. A good framework should support this easy to set, examine and modify the gets-aims and should automatize the calculation of defect rates (Pan et al., 2008; Mukesh, 1997).

(i) Business Working: Sustainable development is not something that a single person can do in isolation. The business process involves many people in many different parts of the organization. An evaluation tool should facilitate the communication of performance information around the organization, providing it effectively for performance goals to be shared. When a performance issue is declared the results of the evaluation requirement be passed on so that the entity with the problem can examine the conclusions and perform further analysis so as to develop its performance.

(ii) Process Analysis: These tools assist in identifying problems with processes such as manufacturing, shipping or order fulfillment. Process analysis tools highlight areas of poor performance and assist in identifying the causes of problems.

(iii) Aggregation Analysis: These tools examine hierarchical or multidimensional aggregations of data.

This is useful for summarizing information at different levels of detail for reporting budgets, sales or inventory data. Items of interest can usually be broken down into more detail. These tools are generally not suitable for process analysis.

Eliminating defects from business process as part of a continuous development process is essential if companies are to remain freeenterprise. While general purpose tools can be improved for defect evaluation, specialized means are convenient that is easy to use, quick to set up and effective at observing defects and classifying their source (Pan et al., 2008; Mukesh, 1997).

According to the authors, Discussions on how to measure the quality of information systems have gone on for several decades, first in the areas of ergonomics, ease-of-use, and human-computer interaction and later in the area of usability. However, recently discussions recur on which measures of usability are suitable and on how to understand the relationship between different measures of usability (Hornbaek, 2006; Irani et al, 2014. To increase the meaningfulness and strategic influence of usability data, the entire construct of usability can be presented as a single dependent variable (usability index) without sacrificing precision (Sauro and Kindlund, 2005).

\section{METHODOLOGY}

\subsection{Providing Digital Internet Access with Structure-Framework}

In the research, the researchers focus on paper reviews and discuss the value of information provided by monitoring, information and decision support systems for production. It begins by defining the concepts of data, information, and value of information.

This is followed by an overview of the technologies used to obtain data in figure 1. After then, the value of information of monitoring systems or manually registered observations is depicted according to three types of benefits: (a) production, management and general decision making, (b) health and welfare and c) economic value, including labor cost savings. Then, the value of information of decision support systems (DSS) and other management information systems (MIS) combining several traits are examined. DSS which described methods presents much useful, reliable and powerful decision (Remenyi et al., 2000; Duffy et al .2009; Irani, et al, 2014). 
Figure 1: The Diagram of DSS (Khademolqorani and Hamadani, 2013)

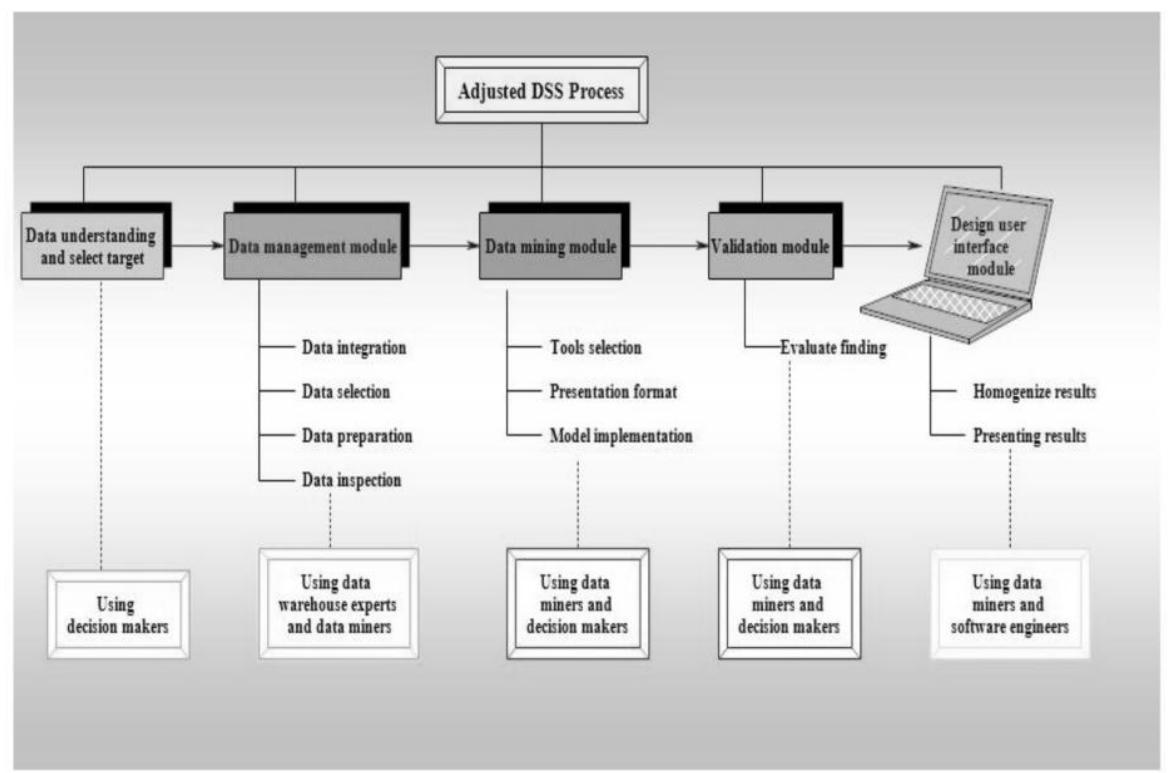

The author emphasizes the fact that Decision support systems are new computerized applications that act as a support system for supporting the organizational and business decision makers in the activities going on in their business and other industries (Druzdzel and Flynn, 2002).In order to adjust the DSS framework concentrating on these requirements. The proposed integrated approach consists of forth major components: data management, data mining, validation, and user interface (Sauter, 1997).

\section{FINDINGS AND DISCUSSIONS}

\subsection{The Purposed Model}

The concept of Internet access began to be studied as versatile (multi-directional ) factors. These are Personal skills, Social and psychological factors, and External factors respectively. Multi-directional (Versatile) review-research includes (i) individual-usage framework, (ii) information framework and (iii) generation framework.

The nature of individuals-usage framework affects the benefits obtained from the internet:

The benefits derived (obtained) from the Internet affect the nature of the individuals-usage framework. This framework involves some factor-criteria. These benefits-criteria (entities) are high social level, income and education, Advanced computer and internet applications, and also access IT -ICT tools easier way / instantly and useful usage targets. Furthermore, Information framework refers that personscompanies have the information acquired in the different depth preventing the information framework too. Even though, Accessing the useful and necessary information is possible in terms of infrastructural, the prevention of the habit of usage of information framework, cognitive skills and their impact on the regulatory authorities to access information also can not be ignored (UNESCO, 2002 and 2005). The differences in the individual skills cause the expansion of the information framework. The purposed model of the information framework is presented as below in figure 2 . This structure includes these criteria in figure 2 .

\section{Figure 2: The Purposed Model of The Information Framework}

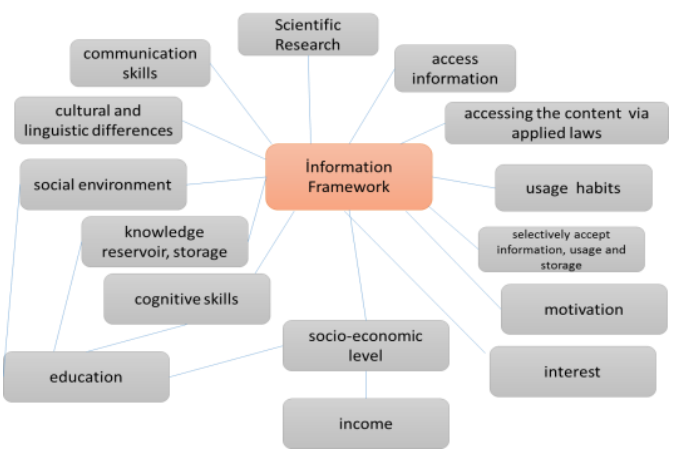

Generation Framework or qualified as participation framework refers that difference of the level of contributing to the digital content by persons. This framework is the newest dimension of the digital structure-framework after the usage Web 2.0 or 3.0 version tools into our 
life. User-friendly content tools, blogs, video sharing and social media sites have the opportunity to create and share the online content for the ordinary people that can be provided to see, serve the broad households (population). The suggested model of the generation framework contains some features. These are an access point, creativity, technological competence, access frequency, technological tools and income which are integrated with this framework. And also The suggested models for Information-Decision Support System (I-DSS) which are named (i) individual-usage framework, (ii) information framework and (iii) generation framework are interconnected with same features-properties (entities). These features-properties are income, education, and access point etc.

Business needs to develop the performance of their business process if they are to remain competitive. Unfortunately, strategic processes such as order fulfillment are complex and hard to analyze. Determining the effectiveness of re-engineering efforts and identifying areas for further development is difficult. However existing business databases include useful information, it is often underutilized, examined because of difficulties in processing data. A new generation of performance analysis tool is facilitating data analysis, making it possible for business get a clear overview of process behavior and define the sources of performance issues (Klein, 1995; Kim and Sanders, 2002).

\section{CONCLUSION}

Recently, Information-Decision Support Systems (DSS) welcomes contributions on the concepts and operational basis for DSSs, In treating DSS topics, manuscripts may draw-on, expand such diverse areas as artificial intelligence, cognitive science, computer supported cooperative work, database management, decision theory, economics, management science and operations management systems (Chandra and Grabis,2008; Soroor et al., 2009). DSS is very vital for these stages:

- identify Mangement Information system (MIS) and its characteristics, - introduce and categorize the critical factors of Supplier and enterprise resource system (SERS) and MIS

- investigate the relation on the performance of supply channel processes performed through SERS.

Identification of new dimensions of the Digital Structure-Framework and taking measures are very important on behalf of the efficient usage of internet by the community and the acceleration of development of the internet. The identification of factors affecting the new numerical (digital) development emerged the result model (purposed model). This model can contribute to detect the weak points of an obstacle to development and to eliminate the development of effective policies. After the solution of the individual-usage framework, it is important to storage and usage the content of information framework. Recovering the useful information and data is one of the important factors for the Society and economic growth. Generation framework is the only dimension which is not connected (associated) with the education feature.

Better management awareness of internal strength and weaknesses and external threats and opportunities. Allows managers' to record experience and use it in future for similar scenarios that may arise within the organization.

\section{REFERENCES}

Aier, S., Fischer, C. (2011). Criteria of progress for information systems design theories. Information Systems E-Business Management 9, 133-172.

Blake, R., Mangiameli, P. (2013). An information systems design theory for strategic decision systems: the case of a candy manufacturer. Northeast Decision Sciences Institute Annual Meeting Proceedings

Chandra C., Grabis, J. (2008). Information technology support for integrated supply chain modeling. Human Systems Management 27, 313.

Druzdzel, M. J., Flynn, R. R. (2002). Decision support systems. Second Edition, Marcel Dekker, Inc.

Hornbaek, K. (2006). Current practice in measuring usability: challenges to studies and research. International Journal of Human-Computer Studies, 64(2), 79-102.

Irani, Z., Sharif, A., Kamal, M. M., E. D. Love, P. (2014). Visualising a knowledge mapping of information systems investment evaluation. Expert Systems with Applications 41, 105-125.

Khademolqorani, S., Hamadani, A. (2013). An adjusted decision support system through data mining and multiple criteria decision making. The 2nd International Conference on Integrated Information, Procedia - Social and Behavioral Sciences 73, 388 - 395.

Kim, Y. J., Sanders, G. L. (2002). Strategic actions in information technology investment based on real option theory. Decision Support Systems 33, 1-11.

Klein, M. (1995). iDCSS: Integrating workflow, conflict and rationale-based concurrent engineering coordination technologies. Concurrent Engineering: Research and Applications 3/1, pp. 21-27.

Laudon K. C., Laudon, J. P. (1988). Management information systems, a contemporary perspective. 3rd ed. Collier Macmillan, New York, 784 p., ISBN-13: 978-0023681011

Liu, S., Duffy A. H. B., Whitfield, R. I., Boyle, I. M. (2009). Integration of decision support systems to improve decision support performance. Knowledge and Information Systems, 22 (3), 261-286.

Meigs, R. F. (1993). Accounting; the basis for basic decisions. McGraw-Hill. NewYork, 159 p., ISBN-13: 978-0070416406 
Mukesh, S. (1997). Defect prevention: reducing cost and improving quality. IEEE Computer 30(8).

Pan, T., Zheng, L., Fang, C. (2008). Defect tracing system based on orthogonal defect classification. Computer Engineering and Applications, 43, 9-10.

Remenyi, D., Money, A., Sherwood-Smith, M., Irani, Z. (2000). The effective measurement and management of IT costs and benefits (2nd ed.). UK: Butterworth Heinemann.

Sauro, J., Kindlund, E. (2005). A method to standardize usability metrics into a single score. CHI Papers: Methods \& Usability, 401-409.

Sauter, V. L. (1997). Decision support systems: an applied managerial approach. John Wiley \& Sons, Inc.

Soroor, J., Tarokh, M. J., Keshtgary, M. (2009). Preventing failure in IT-enabled systems for supply chain management. International Journal of Production Research, 47 (23), 6543-6557.

Suma, V., Gopalakrishnan Nair, T. R. (2008). Effective defect prevention approach in software process for achieving better quality levels. Proceedings of World Academy of Science, Engineering and Technology 32, - August 2008

UNESCO. (2005). Education for all - global monitoring report 2006. UNESCO, France.

UNESCO. (2002). Information and communication technologies in teacher education. A Planning Guide. http://www.ifiptc3.net/IMG/pdf/unesconikki129533e.pdf accessed 10.10.2017. 